\title{
TENSILE TESTS FOR POLYAMIDE 6 AND POLYPROPILENE
}

\author{
Andreea Elena MUSTEATA ${ }^{1}$, George PELIN ${ }^{2}$, \\ Mihail BOTAN ${ }^{2}$, Lorena DELEANU ${ }^{1}$
a "Dunărea de Jos" University of Galati, Faculty of Science and Environment, Galati, Romania
b " National Institute for Aerospace Research "Elie Carafoli", INCAS, Bucharest, Romania \\ * Corresponding author: lorena.deleanu@ugal.ro
}

\begin{abstract}
This paper presents the influence of deformation rate on the stress- strain curves for two polymers, Polyamide 6 (PA6) and polypropylene (PP), tensile samples being supplied by Monofil SRL Săvinești, Romania. Tensile tests were done at INCAS Bucharest and the presented results are values obtained on 5 bone samples. There were analyzed the following characteristics: Young modulus, stress peak at break, elongation at break and energy at break. Greater deformation rates, when testing at traction, rises the tensile stress limit and diminishes the strain at which the polymer samples break. PA6 and PP exhibit different behaviors. PA6 yields at very low deformation rate, having a high strain at break (0.9) when it is tested at $10 \mathrm{~mm} / \mathrm{min}$, but reducing this characteristic for higher deformation rates. PP has similar curves for the tested deformation rates, but with lower tensile stress limit when tested under lower deformation rate. These data are useful when designing polymeric components bearing different strain rates.
\end{abstract}

Keywords: tensile test, PA6, PP, tensile test, energy at break, Young modulus

\section{INTRODUCTION}

Both polymers of interest, polypropylene (PP) and polyamide 6 , are thermoplastics, having a wide range of applications.

$\mathrm{PP}$ is included in the class of polyolefins, has a cristallinity degree of $30 \ldots 60 \%$, depending on processing conditions, but crystalline and amorphous zones in polymer have small differences in density. PP is normally tough and flexible, allowing to be used as an engineering plastic, competing with materials such as acrylonitrile butadiene styrene (ABS) as it has a reasonably price. In a market study [6], [7] PP was reported as the second most important plastic after polyethylene (with low, high and ultra high densities), parts made of it could be processed with many technologies, and used for the most diverse applications, ranging from packaging to household appliances, clothes, and vehicles. One of the recent reports on this market expects a demand for this polymer to grow with 3\% per year until 2024. The world production of PP is 55.9 MMT in 2018 and is estimated to reach 83.17 MMT by 2025 [2]

Polyamide 6 is the most significant construction material used in many industries (automotives, aircrafts, electronics, cloth industry and medicine). In Europe, yearly demand for polyamides tends to rich a million tonnes injection molding [3]. The global polyamide market was valued at USD 25.14 Billion in 2016 and is projected to reach USD 30.76 Billion by 2021 , at a growth rate of $4.1 \%$ from 2016 to 2021 [4].

It shows good coefficient of friction and increases process stability at high processing temperature. It exhibits high impact strength, high stiffness, and excellent wear- and good temperature resistance. Polyamide 6 improves long term heat and stability to ultraviolet and visible light and parts made of it have good toughness and durability [5]. Polyamides [6], [7] endure high temperature and have good electrical resistances, being introduced in transportat industries, house goods, a electrical and electronic applications.

Tensile tests are useful for assessing the material quality and to compare them when the designers have to select one among several grades available on the market [8], [9], [10].

This paper presents the influence of tensile test rate on mechanical characteristics of two polymers: polypropylene (PP) and polyamide 6 (PA6).

\section{MATERIALS AND TESTING METHOD}

The polymer samples were obtained at Monofil Savinesti (Romania) by molding, the laboratory 
method being characteristic for plastic polymers [14]. The tensile tests were performed with the help of a tensile machine (Instron 2736-004, INCAS), using a bone sample type A (SR ISO 527-1), for four test rates $(10 \mathrm{~mm} / \mathrm{min}, 250 \mathrm{~mm} / \mathrm{min}, 500 \mathrm{~mm} / \mathrm{min}$ and $1000 \mathrm{~mm} / \mathrm{min}$, respectively). Five representative tests were selected for calculating the average value of each characteristic.
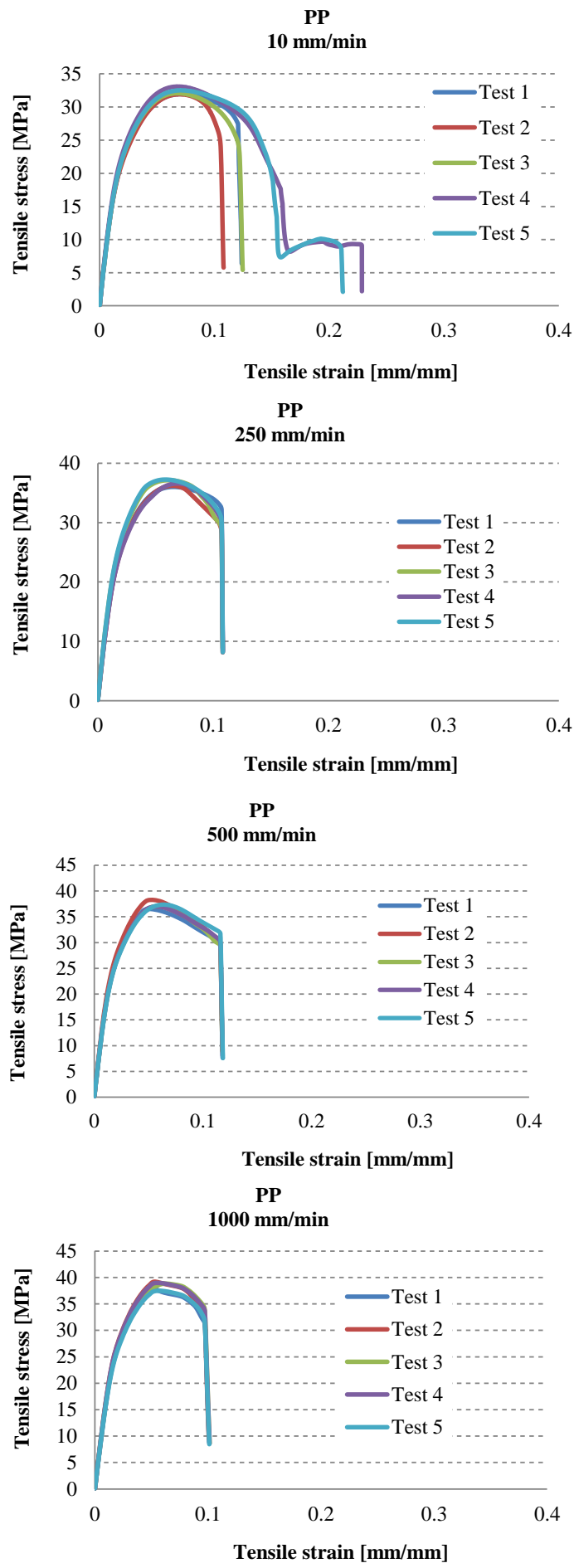

\section{RESULTS}

Values of mechanical characteristics for these two polymers are useful for evaluating their change when blending them [13], [11].

Stress-strain curves for each polymer and test rate are given in Fig. 1.

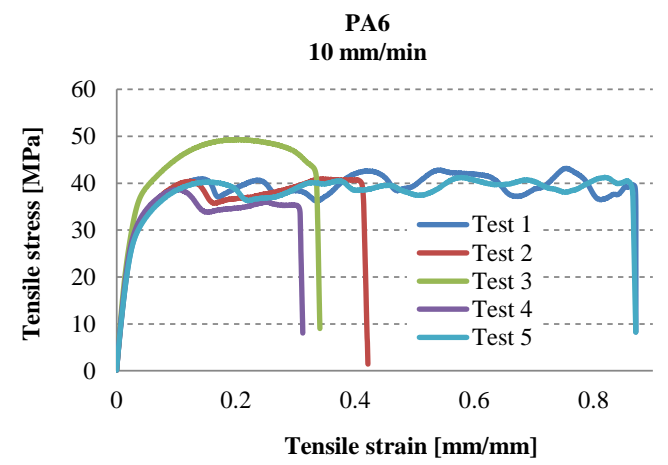

PA6
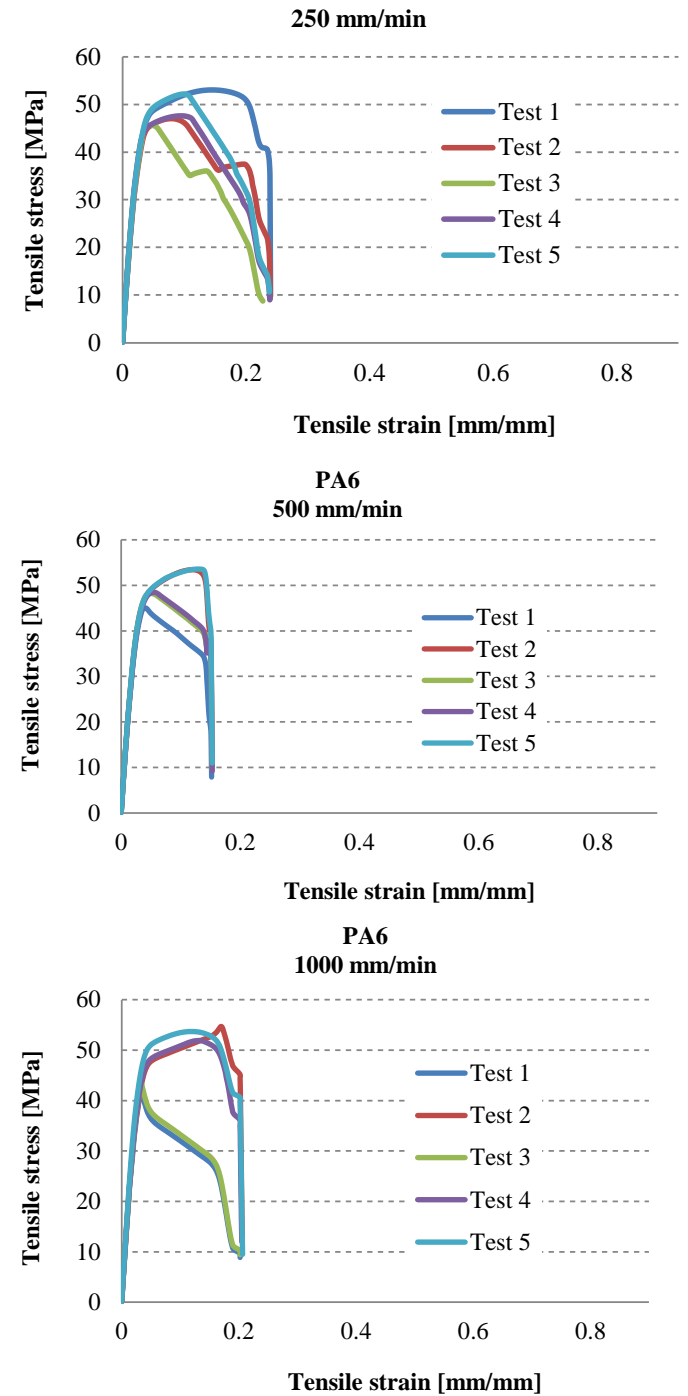

Fig. 1. Stress-strain curves (engineering) 


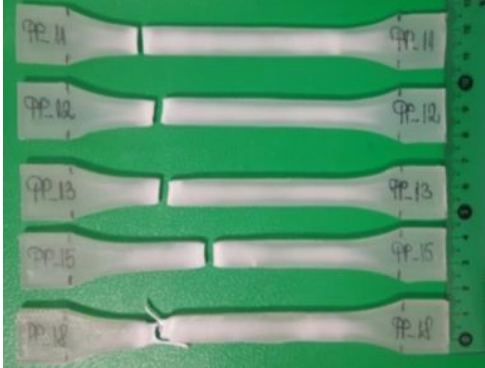

a) $10 \mathrm{~mm} / \mathrm{min}$

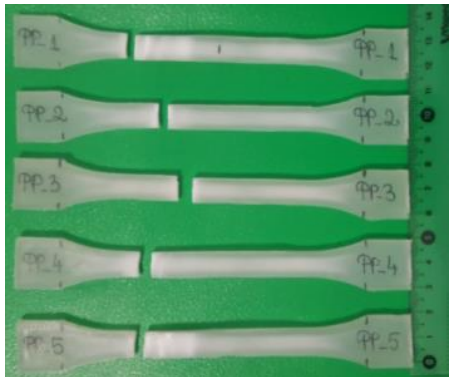

c) $500 \mathrm{~mm} / \mathrm{min}$

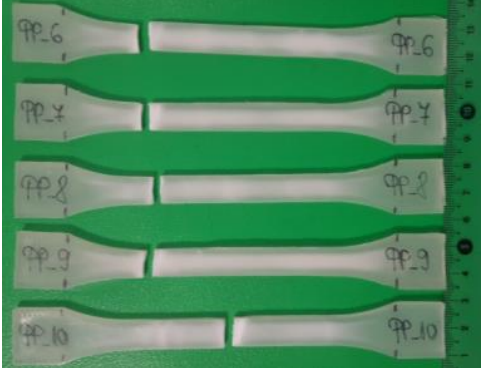

b) $250 \mathrm{~mm} / \mathrm{min}$

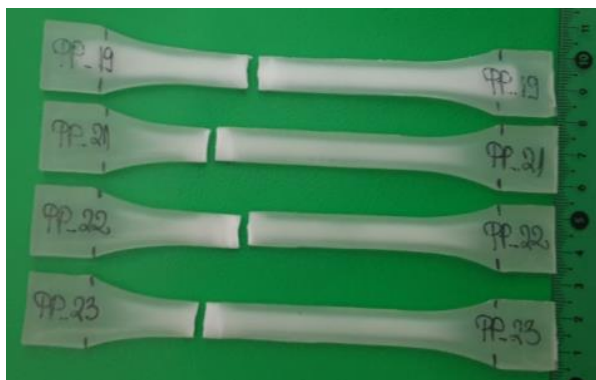

d) $1000 \mathrm{~mm} / \mathrm{min}$

Figure 2. Samples broken after tensile testing, samples made of PP

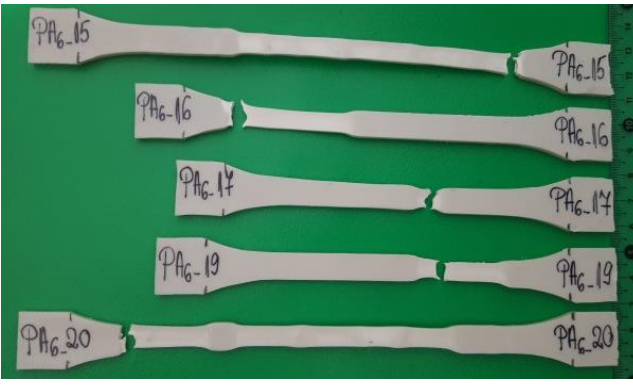

a) $10 \mathrm{~mm} / \mathrm{min}$

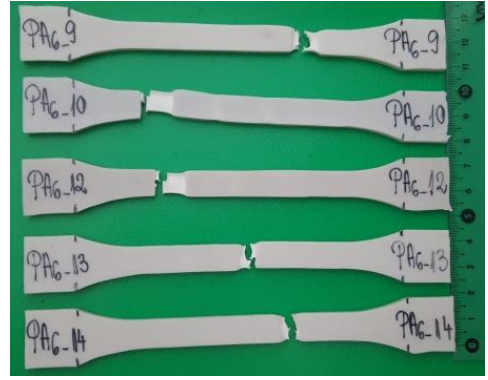

b) $250 \mathrm{~mm} / \mathrm{min}$

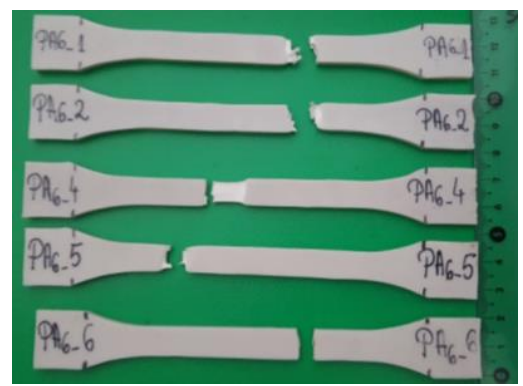

c) $500 \mathrm{~mm} / \mathrm{min}$

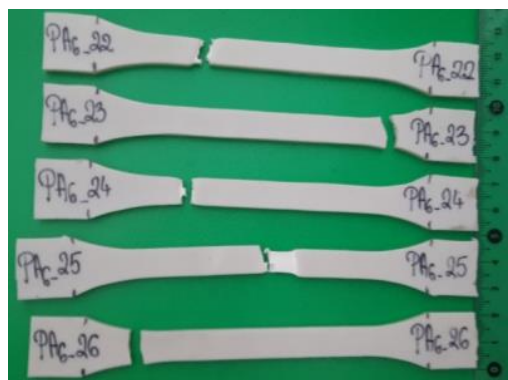

d) $1000 \mathrm{~mm} / \mathrm{min}$

Fig. 3. Samples made of PA6, broken after tensile testing

Figures 2 and 3 present photos of the set of 5 samples for each material and test rate. PP has no local stranglehold, as PA6 does. Opaque white in the core of the tested samples means that PP could bear changes in the cristallinity or/and morphology of the polymer, induced by loading.

At $10 \mathrm{~mm} / \mathrm{min}$, PA6 has no uniform strain at break along the sample and only two samples are similar in aspect, the other having different places where the strangulation occurs.

Comparing the plots in Fig. 1, one may notice that PA6 has higher values for strain at break and this polymer has a diversification of plot shapes, especially for the lowest test rate, $10 \mathrm{~mm} / \mathrm{min}$. In Fig. 1 , from 5 tested samples, two exhibited a flow process till break, the other ones having the same level for flowing, but shorter. For the other test rates, the shape of the stress-strain curves has two regions: one almost linear, the recorded data in this region being in a very narrow band, till around $45 \mathrm{PMa}$, the other having two tendencies: one convex and the other concave.

PP exhibits differences in the curve shape only for $\mathrm{v}=10 \mathrm{~mm} / \mathrm{min}$, three samples having a breaking 
process without a flow (as two of them). For the other test rates, this polymer has a mechanical behavior that overlapps the curves, meaning a more uniform distribution of the crystalline and amorfous regions in the samples.
Tables 1 and 2 present the values for the analyzed characteristics and also the average value, the standard deviation, the maximum and minimum values and the magnitude of the band in which the chracteristic has values.

Table 1. Tensile properties for PA6 v=10 mm/min

\begin{tabular}{|c|c|c|c|c|c|c|c|c|}
\hline \multirow{2}{*}{ Sample } & \multicolumn{4}{|c|}{ Energy at Break [J] } & \multicolumn{3}{c|}{ Tensile stress at Break (Standard) [MPa] } \\
\cline { 2 - 9 } & $\mathbf{1 0}$ & $\mathbf{2 5 0}$ & $\mathbf{5 0 0}$ & $\mathbf{1 0 0 0}$ & $\mathbf{1 0}$ & $\mathbf{2 5 0}$ & $\mathbf{5 0 0}$ & $\mathbf{1 0 0 0}$ \\
\hline 1 & 143.24 & 46.24 & 17.87 & 4.12 & 34.88 & 39.15 & 33.24 & 42.42 \\
\hline 2 & 64.74 & 32.38 & 28.52 & 27.88 & 6.05 & 36.79 & 43.32 & 53.12 \\
\hline 3 & 66.29 & 20.36 & 30.3 & 4.61 & 36.48 & 34.8 & 39.15 & 43.66 \\
\hline 4 & 44.06 & 27.55 & 27.29 & 24.34 & 32.77 & 35.98 & 37.81 & 50.56 \\
\hline 5 & 132.45 & 21.77 & 30.04 & 39.1 & 34.69 & 42.46 & 45.62 & 40.69 \\
\hline Average & $\mathbf{9 0 . 1 5 6}$ & $\mathbf{2 9 . 6 6}$ & $\mathbf{2 6 . 8 0 4}$ & $\mathbf{2 0 . 0 1}$ & $\mathbf{2 8 . 9 7 4}$ & $\mathbf{3 7 . 8 3 6}$ & $\mathbf{3 9 . 8 2 8}$ & $\mathbf{4 6 . 0 9}$ \\
\hline$\sigma$ & 39.867 & 9.332 & 4.597 & 13.673 & 11.522 & 2.715 & 4.328 & 4.856 \\
\hline Max & 143.24 & 46.24 & 30.3 & 39.1 & 36.48 & 42.46 & 45.62 & 53.12 \\
\hline Min & 44.06 & 20.36 & 17.87 & 4.12 & 6.05 & 34.8 & 33.24 & 40.69 \\
\hline Range & 99.18 & 25.88 & 12.43 & 34.98 & 30.43 & 7.66 & 12.38 & 12.43 \\
\hline
\end{tabular}

\begin{tabular}{|c|c|c|c|c|c|c|c|c|}
\hline \multirow{2}{*}{ Sample } & \multicolumn{4}{|c|}{ Tensile strain at Break [\%] } & \multicolumn{4}{c|}{ Modulus (Young's) [MPa] } \\
\cline { 2 - 9 } & $\mathbf{1 0}$ & $\mathbf{2 5 0}$ & $\mathbf{5 0 0}$ & $\mathbf{1 0 0 0}$ & $\mathbf{1 0}$ & $\mathbf{2 5 0}$ & $\mathbf{5 0 0}$ & $\mathbf{1 0 0 0}$ \\
\hline 1 & 87.15 & 23.66 & 11.18 & 3.56 & $1,347.49$ & $1,924.33$ & $1,739.34$ & $1,806.02$ \\
\hline 2 & 41.66 & 19.25 & 14.58 & 13.59 & $1,411.09$ & $1,811.16$ & $1,950.16$ & $1,853.72$ \\
\hline 3 & 33.62 & 13.27 & 18.47 & 3.86 & $1,582.17$ & $1,809.43$ & $1,853.69$ & $1,777.71$ \\
\hline 4 & 30.82 & 16.7 & 16.57 & 12.7 & $1,497.72$ & $1,701.20$ & $1,881.51$ & $1,837.83$ \\
\hline 5 & 86.68 & 12.02 & 14.98 & 20.17 & $1,382.08$ & $1,929.38$ & $1,995.97$ & $1,884.71$ \\
\hline Average & $\mathbf{5 5 . 9 8 6}$ & $\mathbf{1 6 . 9 8}$ & $\mathbf{1 5 . 1 5 6}$ & $\mathbf{1 0 . 7 7 6}$ & $\mathbf{1 4 4 4 . 1 1}$ & $\mathbf{1 8 3 5 . 1}$ & $\mathbf{1 8 8 4 . 1 3}$ & $\mathbf{1 8 3 1 . 9 9}$ \\
\hline$\sigma$ & 25.503 & 4.200 & 2.414 & 6.320 & 85.097 & 84.866 & 88.051 & 37.165 \\
\hline Max & 87.15 & 23.66 & 18.47 & 20.17 & 1582.17 & 1929.38 & 1995.97 & 1884.71 \\
\hline Min & 30.82 & 12.02 & 11.18 & 3.56 & 1347.49 & 1701.2 & 1739.34 & 1777.71 \\
\hline Range & 56.33 & 11.64 & 7.29 & 16.61 & 234.68 & 228.18 & 256.63 & 107 \\
\hline
\end{tabular}

Table 2. Tensile properties for PP

\begin{tabular}{|c|c|c|c|c|c|c|c|c|}
\hline \multirow{2}{*}{ Sample } & \multicolumn{4}{|c|}{ Energy at Break [J] } & \multicolumn{3}{c|}{ Tensile stress at Break (Standard) [MPa] } \\
\cline { 2 - 10 } & $\mathbf{1 0}$ & $\mathbf{2 5 0}$ & $\mathbf{5 0 0}$ & $\mathbf{1 0 0 0}$ & $\mathbf{1 0}$ & $\mathbf{2 5 0}$ & $\mathbf{5 0 0}$ & $\mathbf{1 0 0 0}$ \\
\hline 1 & 13.14 & 13.37 & 15.8 & 12.91 & 27.41 & 33.14 & 31.43 & 35.1 \\
\hline 2 & 11.69 & 10.76 & 10.64 & 9.4 & 22.85 & 32.22 & 35.74 & 38.78 \\
\hline 3 & 13.83 & 10.97 & 10.45 & 12.05 & 21.6 & 35.14 & 35.05 & 36.35 \\
\hline 4 & 19.45 & 11.38 & 11.8 & 12.36 & 9.07 & 33.91 & 33.65 & 35.35 \\
\hline 5 & 19.18 & 12.92 & 15.38 & 10.29 & 8.48 & 32.8 & 31.97 & 36.06 \\
\hline Average & $\mathbf{1 5 . 4 5 8}$ & $\mathbf{1 1 . 8 8}$ & $\mathbf{1 2 . 8 1 4}$ & $\mathbf{1 1 . 4 0 2}$ & $\mathbf{1 7 . 8 8 2}$ & $\mathbf{3 3 . 4 4 2}$ & $\mathbf{3 3 . 5 6 8}$ & $\mathbf{3 6 . 3 2 8}$ \\
\hline$\sigma$ & 3.225 & 1.061 & 2.317 & 1.330 & 7.685 & 1.009 & 1.676 & 1.307 \\
\hline Max & 19.45 & 13.37 & 15.8 & 12.91 & 27.41 & 35.14 & 35.74 & 38.78 \\
\hline Min & 11.69 & 10.76 & 10.45 & 9.4 & 8.48 & 32.22 & 31.43 & 35.1 \\
\hline Range & 7.76 & 2.61 & 5.35 & 3.51 & 18.93 & 2.92 & 4.31 & 3.68 \\
\hline
\end{tabular}




\begin{tabular}{|l|r|r|r|r|r|r|r|r|}
\hline \multirow{2}{*}{ Sample } & \multicolumn{9}{|l}{ Tensile strain at Break [\%] } & \multicolumn{1}{l|}{ Modulus (Young's) [MPa] } \\
\cline { 2 - 10 } & $\mathbf{1 0}$ & $\mathbf{2 5 0}$ & $\mathbf{5 0 0}$ & $\mathbf{1 0 0 0}$ & $\mathbf{1 0}$ & $\mathbf{2 5 0}$ & \multicolumn{1}{|l|}{$\mathbf{5 0 0}$} & \multicolumn{1}{c|}{$\mathbf{1 0 0 0}$} \\
\hline 1 & 12.05 & 10.5 & 12.12 & 9.54 & $1,630.51$ & $1,799.90$ & $1,800.46$ & $1,794.97$ \\
\hline 2 & 10.55 & 8.75 & 8.45 & 7.34 & $1,639.11$ & $1,812.45$ & $1,839.50$ & $1,808.77$ \\
\hline 3 & 12.21 & 9.1 & 8.27 & 8.92 & $1,609.73$ & $1,849.17$ & $1,788.04$ & $1,789.18$ \\
\hline 4 & 22.83 & 8.97 & 9.18 & 9.25 & $1,685.37$ & $1,812.20$ & $1,758.05$ & $1,813.46$ \\
\hline 5 & 21.02 & 10.64 & 11.54 & 7.88 & $1,630.50$ & $1,908.73$ & $1,815.19$ & $1,744.09$ \\
\hline Average & $\mathbf{1 5 . 7 3 2}$ & $\mathbf{9 . 5 9 2}$ & $\mathbf{9 . 9 1 2}$ & $\mathbf{8 . 5 8 6}$ & $\mathbf{1 6 3 9 . 0 4}$ & $\mathbf{1 8 3 6 . 4 9}$ & $\mathbf{1 8 0 0 . 2 4}$ & $\mathbf{1 7 9 0 . 0 9}$ \\
\hline$\sigma$ & 5.12 & 0.807 & 1.605 & 0.838 & 25.104 & 39.714 & 27.179 & 24.640 \\
\hline Max & 22.83 & 10.64 & 12.12 & 9.54 & 1685.37 & 1908.73 & 1839.5 & 1813.46 \\
\hline Min & 10.55 & 8.75 & 8.27 & 7.34 & 1609.73 & 1799.9 & 1758.05 & 1744.09 \\
\hline Range & 12.28 & 1.89 & 3.85 & 2.2 & 75.64 & 108.83 & 81.45 & 69.37 \\
\hline
\end{tabular}

\section{PA6}

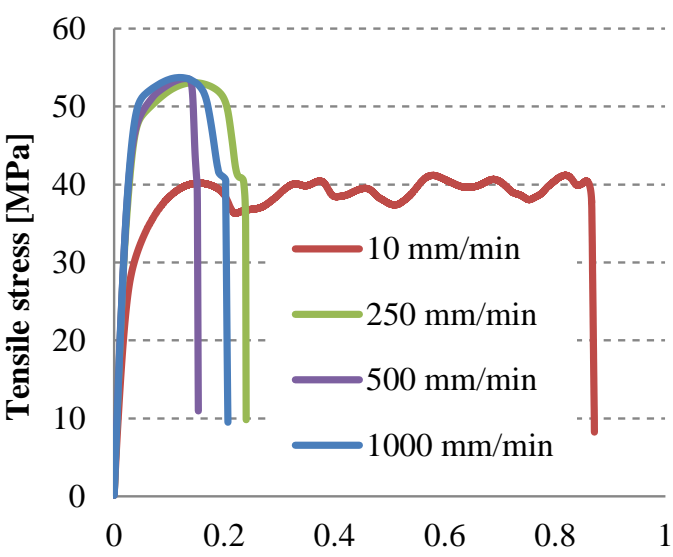

Tensile strain $[\mathrm{mm} / \mathrm{mm}]$

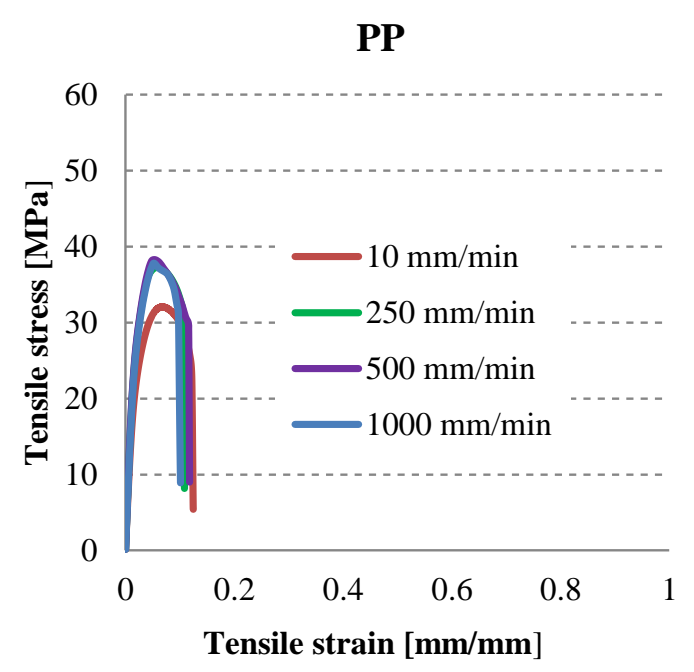

b)

Fig. 4. Typical curves stress -strain

The standard deviation, $\sigma$, was calculted with the relation

$$
\sigma=\sqrt{\frac{\sum_{i=1}^{N}\left(x_{i}-\bar{x}\right)^{2}}{N}}
$$

where $N$ is the number of tested samples, $x_{i}$ is the value of the characteristic obtained for the sample $\mathrm{i}$ and $\bar{x}$ is the arithmetical average for the $\mathrm{N}$ values:

$$
\bar{x}=\left(\sum_{i=1}^{N} x_{i}\right) / N
$$

Figure 4 is pointing out the difference in mechanical behavior of the two polymers. At low test rates (including $10 \mathrm{~mm} / \mathrm{min}$ ), PA6 has low limit at break and a plastic flow starting at $0.1 \ldots 0.15$ strain. At higher rates this flowing plateau, even weavy, disappeared and the limit at break is very less sensitive to the test rate. PP exibits close values for the strain at break, with no evident dependence on test rate. Only the tensile stress at break is lower for $10 \mathrm{~mm} / \mathrm{min}$ (a maximum of $27.41 \mathrm{MPa}$, sample 1 in Table 2 and a minimum of $8.48 \mathrm{MPa}$ ), but the other test rates, the values are in a narrow interval (3...5 $\mathrm{MPa}$ ).

Based on experimental results, there could be created constitutive models for simulating the complex behavior when plastics are subjected to large strain rates, as in impact cases [12].

\section{CONCLUSIONS}

The authors extracted a typical curve for each tested set of five samples for each tested rate and plotted on the same graphic in order to point out the influence of the test rate. Except for $\mathrm{v}=10 \mathrm{~mm} / \mathrm{mm}$, PA6 has the stress-strain curves engage over till the highest value of stress before breaking, but the strain at break performs for different values, from 3 to $20 \%$. 
The shape of the stress-strain curve of PP seams to be less sensitive to the test rate, except for $\mathrm{v}=10$ $\mathrm{mm} / \mathrm{min}$ when the tensile stress at break is lower than those for the other test rates.

The influence of test rate on each tensile characteristics is given in Fig. 5. One may notice that the differences are greater when comparing the values obtained for the lowest test rate to those resulting for tests done at $\mathrm{v}=250 \mathrm{~mm} / \mathrm{min}$. For all analyzed characteristics, their gradient in this test rate interval is the greater. For $v=250 \ldots 1000 \mathrm{~mm} / \mathrm{min}$, the influence of the test rate is less marked on the values.

The stress at break increase more for PA6, but the two polymers have similar evolution.

The energy at break is higher for PA6, but PP seems to be indifferent to the increase of test rate and keeps the strain at break in a $2 \%$ interval.

The values for Young modulus are very close for both polymers.

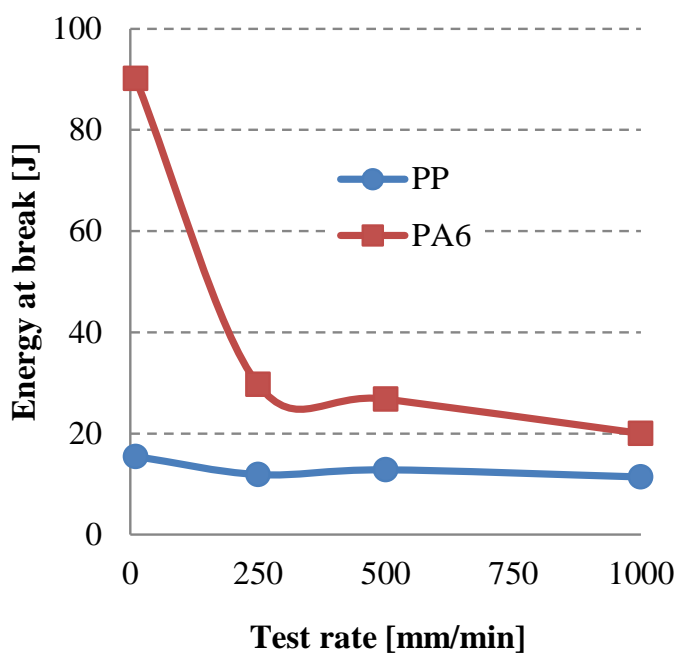

a)

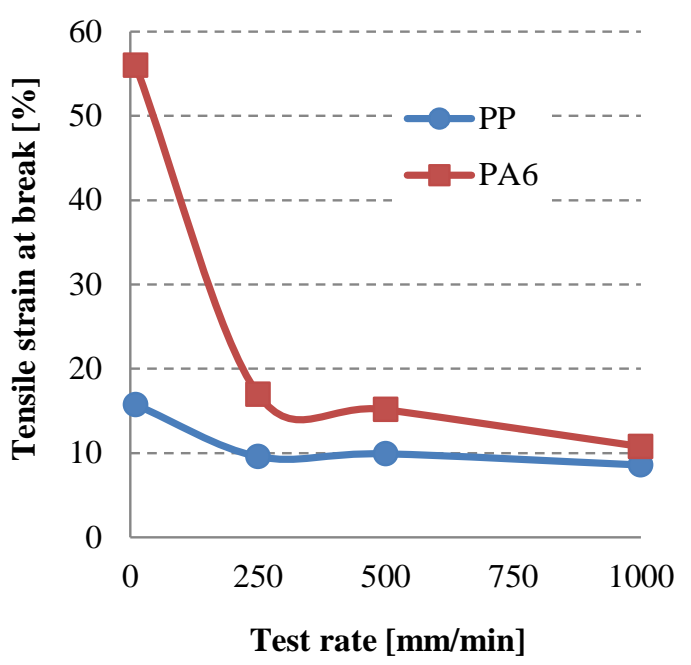

c)
For the tested polymers ( $\mathrm{Pa} 6$ and $\mathrm{PP})$, mechanical characteristics in tensile loading are dependent on the test rate, but each in different way.

Mechanical characteristics of polymers do not presents the same dependence on test rate, and the results of comparing PP and PA6 argued this conclusions.

The results are useful in designing mathematical models for simulating the behavior of a particular polymeric material under different strain rates, especially under impact. But these tests cover only low velocity impact applications and the tendency to increase the stress at break or to decrease the strain at break is valid only for the tested rates, for applications far from these values, adequate tests are requested.

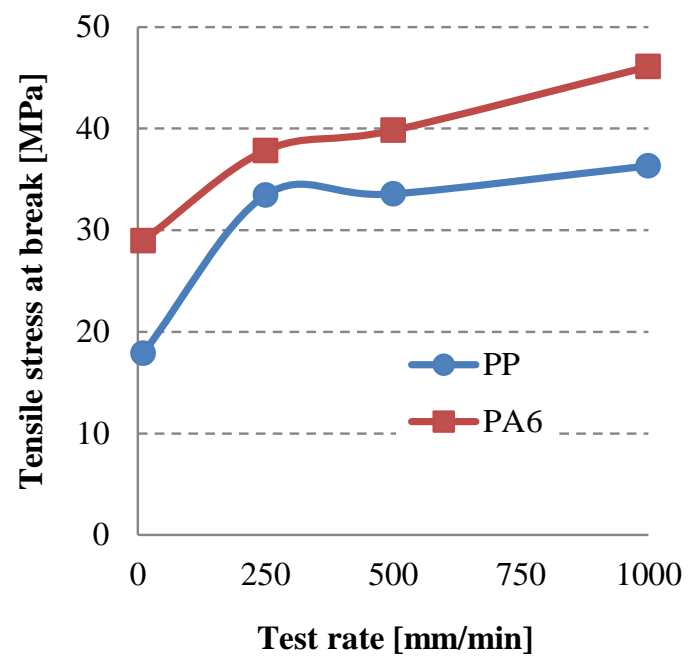

b)

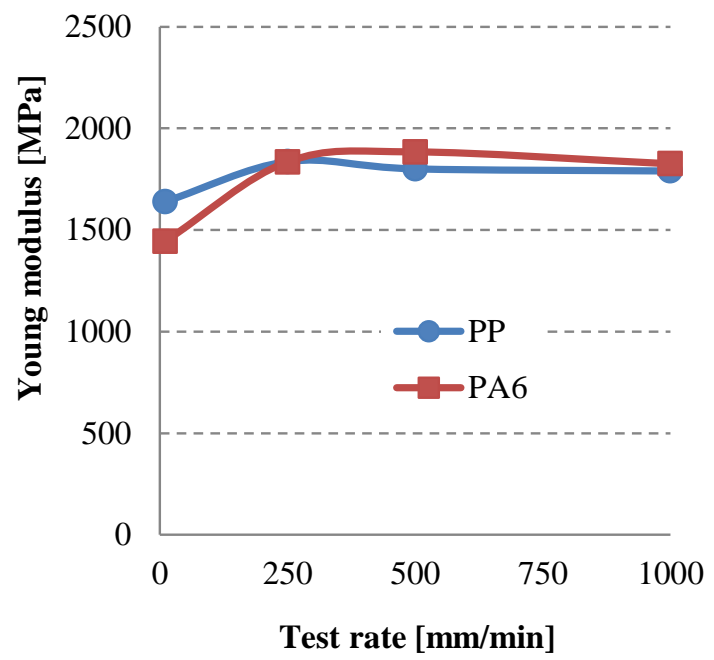

d)

Fig. 5. Influence of the test rate on several tensile characteristics 
This paper presented the mechanical characteristics of PP and PA6 for a future study implying PP+PA6 blends for protection against low velocity impact, better and higher quality of processability by molding and to shield some dezadvantages of the component (poor dimensional stability, water absortion etc.).

\section{ACKNOWLEGMENT}

This paper was supported by Doctorale School for Mechanical and Industrial Engineering of "Dunarea de Jos" University of Galati.

\section{REFERENCES}

1. *** Global Polypropylene (PP) Market Size, Demand Forecasts, Industry Trends \& Updates (2018-2025), ResearchAndMarkets.com, https://www.businesswire.com/news/home/20181 008005560/en/Global-Polypropylene-PP-MarketSize-Demand-Forecasts

2. Polypropylene Market Report, https://www.ceresana.com/en/marketstudies/plastics/polypropylene/

3. Fischer M., (2004) Polyamides (PA). High increase in consumption, Kunststoffe plast Europe, $\quad$ pp 1-4, file://C:/Downloads/High\%20Increase $\% 20 \mathrm{in} \% 20$ Consumption_\%20Polyamides\%20(PA).pdf

4. *** Polyamide Market by Application (Engineering Plastics, Fiber), Type (PA 6, PA 66, Bio-based \& Specialty Polyamides), and Region (Asia-Pacific, North America, Europe, Middle East \& Africa, South America) - Global forecast to 2021 , https://www.marketsandmarkets.com/MarketReports/global-nylon-market930.html?gclid=CjwKCAjwk93rBRBLEiwAcMa pUfAqYN2pDuqhy0TBTZMsFTrH0SiVMcTshi_cfZKD3rb4wPb3KYyjhoCPHUQAvD_Bw $\mathrm{E}$

5. *** Polyamide Properties, Production, Price, Market, and Uses, https://www.plasticsinsight.com/resinintelligence/resin-prices/polyamide/\#history

6. Mark J. E. (2007) Physical properties of polymers handbook, Springer.

7. Crawford R. J., 2005, Plastics engineering, 3rd ed., Amsterdam, Boston, online resource: Elsevier Butterworth-Heinemann.

8. Ashby M.F. (2004) Materials Selection in Mechanical Design, 4th ed., ButterworthHeinemann; 4 edition

9. Brown R., (2002) Handbook of polymer testing: short-term mechanical tests : Rapra technology.

10. Shah V. (2007) Handbook of plastics testing and failure analysis, 3rd Ed., John Wiley \& Sons, INC., Publication.
11. S.-L. Bai, C. G'Sellb, J.-M. Hiver, C. Mathieu, (2005) Polypropylene/polyamide6/polyethyleneoctene elastomer blends. Part 3. Mechanisms of volume dilatation during plastic deformation under uniaxial tension, Polymer, 46, pp. 64376446

12. C. Pirvu, A. E. Musteata, G. G. Ojoc, S. Sandu, L. Deleanu (2019) A meso level fe model for the impact bullet - yarn, Revista de materiale Plastice, vol. 56, no. 1, pp. 22-31.

13. Gnatowski A., Koszkul J. (2006) Investigation on PA/PP mixture properties by means of DMTA method, Journal of Materials Processing Technology, 175, pp. 212-217

14. Harper C. A. (2006) Handbook of plastics technologies: the complete guide to properties and performance: Introduction to Polymers and Plastics, Columbus: McGraw-Hill Companies. 